\title{
Patterns of cognitive function in middle- aged and elderly Chinese adults-findings from the EMCOA study
}

\author{
Yu $\mathrm{An}^{1 \dagger}$, Lingli Feng ${ }^{1,2 \dagger}$, Xiaona Zhang ${ }^{1}$, Ying Wang ${ }^{1}$, Yushan Wang ${ }^{1}$, Lingwei Tao ${ }^{1}$, Yanhui Lu ${ }^{1,3}$,
} Zhongsheng Qin $^{4}$ and Rong Xiao ${ }^{1 *}$ iD

\begin{abstract}
Background: The principal aim of this study was to demonstrate the gender-specific cognitive patterns among middle-aged and elderly Chinese adults, investigate the risk factors on global and domain-specific cognitive performance in men and women, respectively, and report demographically adjusted norms for cognitive tests.

Methods: The Effects and Mechanism of Cholesterol and Oxysterol on Alzheimer's disease (EMCOA) study enrolled 4573 participants aged 50-70 years in three Chinese cities. All participants underwent an extensive neuropsychological test battery. Composite scores for specific domains were derived from principal component analysis (PCA). Multivariate linear regression models were used to determine gender-specific risk factors and demographically adjusted normative data.

Results: Three cognitive domains of verbal memory, attention/processing speed/executive function, and cognitive flexibility were extracted. A female advantage in verbal memory was observed regardless of age, whereas men tended to outperform women in global cognition and attention/processing speed/executive function. The effects of education on women were more substantial than men for general cognition and attention/processing speed/executive function. For all the cognitive tests, regression-based and demographically adjusted normative data were calculated.

Conclusions: There is a need for gender-specific intervention strategies for operationalizing cognitive impairment. Trial registration: EMCOA, ChiCTR-OOC-17011882. Retrospectively registered on 5 July 2017.

Keywords: Cognitive pattern, Gender-specific, Global and domain-specific, Normative data, Cross-sectional, Middle-aged and elderly
\end{abstract}

\section{Background}

According to the World Alzheimer Report 2015 released by Alzheimer's Disease International (ADI), 900 million people aged 60 years or above are now living worldwide, with this number expected to increase by $138-239 \%$ in middle-income countries such as China between 2015 and 2050 [1]. This is a noteworthy estimation given that normal aging is accompanied by deterioration across a spectrum of cognitive functions related to memory, attention, executive function, processing speed, and so on

\footnotetext{
* Correspondence: xiaor22@ccmu.edu.cn

${ }^{\dagger}$ Yu An and Lingli Feng contributed equally to this work.

${ }^{1}$ School of Public Health, Capital Medical University, No.10 Xitoutiao, You An Men Wai, Beijing 100069, China

Full list of author information is available at the end of the article
}

[2]. As a chronic and progressive neurodegenerative disorder that is strongly age-associated, dementia involves a severe loss of cognitive function beyond the normal aging process [3]. It can impede independent living and impose considerable personal, social, and economic burdens. Age-related cognitive impairment and the global impact of dementia has become a priority public health issue considering that the aging population constitutes a rapidly increasing proportion of the total population [4]. In the absence of an effective treatment, there is a responsibility for researchers to develop strategies to reduce the risk and slow the progression associated with mental aging.

Research on age-related cognitive impairment has shown that assessment of cognitive performance over 
the lifespan is a heterogeneous process [5]. On one hand, advanced age conveys positive influences on verbal abilities and production, and implicit and autobiographical memory due to growing knowledge and life experience. On the other hand, advanced age also conveys negative influences on processing speed, explicit memory, and verbal fluency due to age-related deterioration of the brain [6]. Diversity in cognitive performance and different rates of cognitive decline have been reported to be altered with regard to demographic characteristics, education, lifestyle, physical conditions, social engagement, and economic resources [7-9]. In fact, the influence of these sociodemographic characteristics on cognitive function is not homogeneous and they may interact with each other to yield distinctive patterns of cognitive performance. In particular, our previous studies have found that numerous cognitive scores were significantly different between men and women [10]. Lifestyle risk factors for mild cognitive impairment (MCI) are also gender-specific, in which smoking was only significant in men [11]. However, the gender-specific cognitive patterns and related risk factors are still under debate with respect to discrepant results across countries and are thus in need of further investigation. The elucidation of these different effects is crucial for understanding what determines healthy cognitive aging.

Including an estimated 218 million older people and 9.5 million people living with dementia, China has become a region with the most people living with dementia in 2015 [1]. Given this, many studies focused on older individuals in different stages of dementia, such as MCI [12-14]. Nevertheless, cognitive aging may begin in mid-life and has also been extensively investigated outside the context of dementia. Therefore, detection of cognitive decline in at-risk middle-aged and elderly groups has become a research priority [15]. Making firm identification and diagnosis between normal aging, MCI, and different subtypes of dementia requires the use of normative standards. Unbiased identification and diagnosis requires an individual's cognitive performance to be compared to a normal sample from a comparable cognitively healthy population [16]. However, most commonly used neuropsychological tests only have norms for elderly populations aged 60 years or above. The norms for cognitive function are relatively underresearched among Chinese middle-aged and elderly adults owing to the lack of large-scale community-based studies. It can be problematic to draw clinical inferences from normative studies only for elderly populations aged 60 years or above.

A large-scale community-based study in China, the Effects and Mechanisms of Cholesterol and Oxysterol on Alzheimer's disease (EMCOA) study, offers an opportunity to explore normal cognitive performance across the age spectrum of 50-70 years. This epidemiological investigation, begun in 2014, was primarily designed to prospectively determine the effects of dietary cholesterol and oxysterols on the incidence of Alzheimer's disease $(\mathrm{AD}) / \mathrm{MCI}$ in the middle-aged and elderly population. The present study emerged to investigate gender-specific cognitive patterns, explore risk factors for global or domain-specific cognitive performance in men and women, respectively, and to establish reliable normative information in Chinese middle-aged and elderly adults.

\section{Methods \\ Setting}

The present study was within the framework of the EMCOA study, an ongoing community-based cohort study of Chinese adults aged 50-70 years living in three Chinese cities of Beijing, Linyi, and Jincheng, and was registered on the Chinese Clinical Trial Registry as ChiCTR-OOC17011882. The baseline examination took place between January 2014 and December 2015 and follow-up examinations take place every 2 years. The project was conducted by a synergistic collaboration among the Capital Medical University, Linyi Health Examination Center affiliated with Linyi People's Hospital, Jincheng Health Examination Center affiliated with Jincheng People's Hospital, and several community-based health centers affiliated with Beijing Chaoyang District Center for Disease Control and Prevention. Eligibility criteria for the EMCOA study included adults aged $50-70$ years with no history of neuropsychiatric disorders or neoplastic diseases (malignant and benign tumor growths, e.g. head-neck tumors, metastatic lung, or upper digestive tumors) [17] and who simultaneously agreed to participate in the study. Exclusion criteria were as follows: 1) diagnosed with any neurodegenerative disease by neurologists (e.g., MCI or dementia); 2) suffering from cognitive impairment caused by depression, stroke, traumatic brain injury, or other severe organ dysfunction; 3) declined to participate in the study; 4) currently taking medication or dietary supplement to improve cognitive function; and 5) uncorrected visual or hearing impairment. The study protocols of the EMCOA study were reviewed and approved by the Ethics Committee of the Capital Medical University (2013SY35) and participants provided written informed consent.

\section{Study population}

The present analysis is based on the information obtained at the baseline examination. A total of 5805 individuals responded to the invitation and agreed to participate in this study. After checking the participants, 1232 participants were excluded for the following reasons: 531 due to neuropsychiatric problems (e.g., 
dementia, depression, or cerebral aneurysm), 680 due to the participant's failure to complete the whole examination, and 21 due to other reasons. Finally, large cross-sectional data from 4573 middle-aged and elderly participants entered the study and were used for this analysis (Fig. 1). Of the 4573 participants, 2247 (49.1\%) were men and 2326 (50.9\%) were women.

\section{Cognitive test battery}

Participants underwent neuropsychological evaluation in a private and quiet room carried out by technicians with formal training. A battery of well-validated Chinese version tests that possess high inter- and intra-rater reliability were administered to assess cognitive performance. Audio tape recordings of standardized testing procedures were reviewed across study sites to ensure consistency. We included the following cognitive tests: the Mini-Mental State Examination (MMSE) [18]; the Montreal Cognitive Assessment Test (MoCA) [19]; the Auditory Verbal Learning Test (AVLT) [20] using summarized scores of immediate recall (AVLT-IR), short recall (AVLT-SR), and long recall (AVLT-LR); the Symbol Digit Modalities Test (SDMT) [21]; the Wechsler Memory Scale Revised for China (WMS-RC) subtests Logical Memory Test-immediate recall (LMT-IR) [22], Digit Span Forwards (DSF), and Digit Span Backwards (DSB) [23]; the Trail Making Test (TMT) A and B [24]; and the Stroop Color-Word Test-Interference Trial (SCWT-IT) [25]. A detailed description of the procedure and modifications made to these measures can be found in Additional file 1: Supplementary methods and results.

\section{Covariates}

At enrollment, a questionnaire on sociodemographics (gender, date of birth, years of formal education, employment, monthly household income, etc.), lifestyle (residence status, reading habits, physical activity, smoking, drinking, etc.), and clinical data (past and family medical history) was used to obtain information from the participants and/or their family member. Details of covariates are shown in Additional file 1.

\section{Data analysis}

Principal component analysis (PCA) with varimax rotation was employed as a data-reduction technique to obtain composite scores for specific cognitive domains. The analysis of covariance was used to compare cognitive patterns between men and women. Sociodemographic characteristics, lifestyle, and medical variables, as well as cognitive performance between men and women, are reported as mean (standard deviation (SD)), median (interquartile range), or frequency (percentage). Reported $p$ values refer to the Student $t$ test, Mann Whitney $U$ test, Kruskal-Wallis test, or chi-square test as appropriate. We used multivariate linear regression analysis for global and domain-specific cognitive performance as continuous outcomes. All models were adjusted for potential risk factors (sociodemographic characteristics, lifestyle, and medical variables) and stratified by gender. Heterogeneity of risk factors between men and women was assessed as gender $\times$ risk factor interactions which were included in overall models with the main effect terms. For interactions in multiple testing, an adjusted $p$ value $<0.05$, taking into

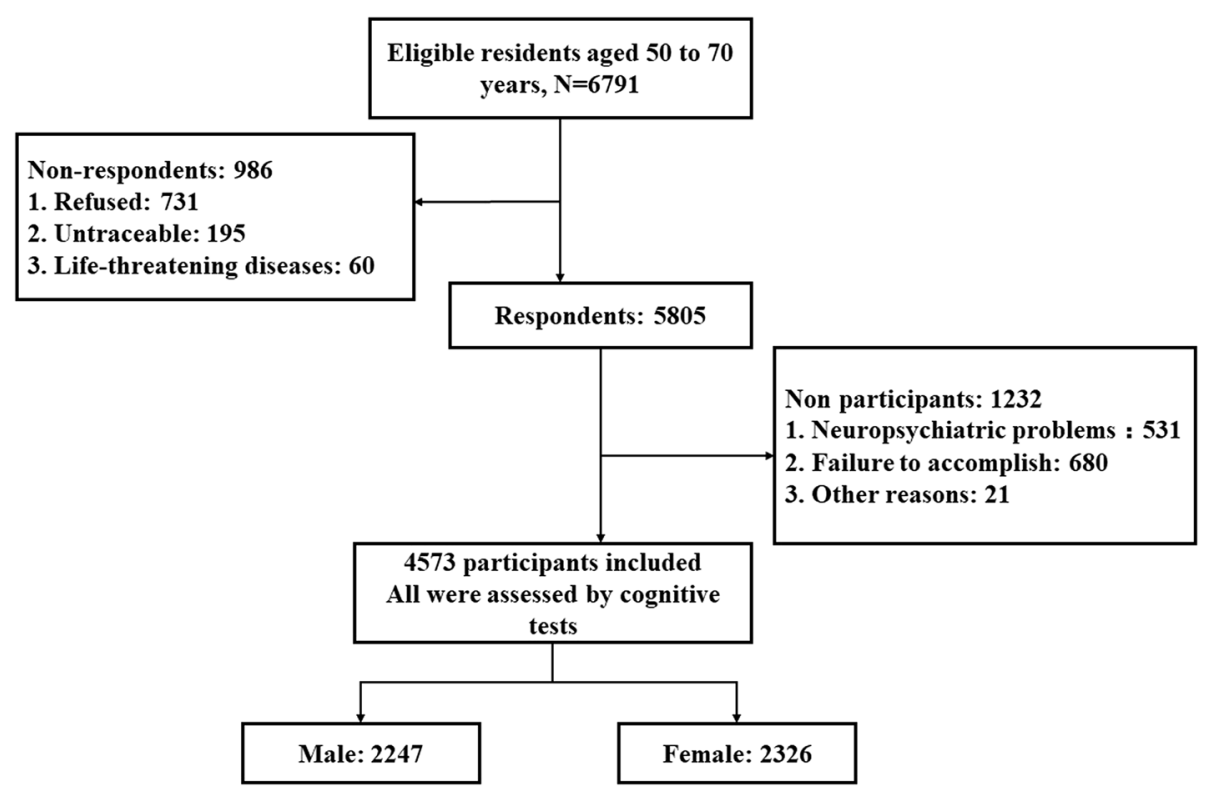

Fig. 1 Study flow chart 
Table 1 Cognitive tests of participants

\begin{tabular}{lllll}
\hline Cognitive test & Total number & Mean & SD & Skew \\
\hline MMSE & 4494 & 28.11 & 2.137 & -2.217 \\
MoCA & 4514 & 24.79 & 3.568 & -1.242 \\
AVLT-IR & 4495 & 15.2209 & 4.98377 & 0.265 \\
AVLT-SR & 4483 & 5.23 & 2.522 & 0.040 \\
AVLT-LR & 4452 & 4.57 & 2.759 & 0.127 \\
SDMT & 4492 & 33.63 & 11.453 & 0.158 \\
DSF & 3923 & 7.72 & 1.448 & -0.735 \\
DSB & 3920 & 4.03 & 1.292 & -0.302 \\
TMT-A & 4486 & 69.75 & 27.295 & 1.029 \\
TMT-B & 4452 & 168.16 & 70.199 & 1.013 \\
LMT-IR & 4427 & 10.7408 & 5.10170 & -0.067 \\
SCWT-IT & 4410 & 40.2502472 & 23.16964651 & 10.304 \\
\hline
\end{tabular}

Skew $>0$, positive skewed distribution; skew $<0$, negative skewed distribution AVLT-IR Auditory Verbal Learning Test-immediate recall, AVLT-LR Auditory Verbal Learning Test-long recall, AVLT-SR Auditory Verbal Learning Test-short recall, DSB digit span backwards, DSF digit span forwards, MMSE Mini-Mental State Examination, MoCA Montreal Cognitive Assessment, SCWT-IT Stroop Color-Word Test Interference Trial, SDMT Symbol Digit Modalities Test, TMT Trail Making Test, LMT-IR Logical Memory Test-immediate recall

account the false discovery rate (FDR) [26], was considered as statistically significant. The norms of these cognitive tests were also established and stratified according to variables that most associated with cognitive performance, and the details are shown in Additional file 1. All analyses were carried out using SPSS for Windows, version 23.0 (SPSS, Chicago, IL USA) and statistical significance was set at $p<0.05$.

Table 2 Principal components analysis for the cognitive subtests

\begin{tabular}{llll}
\hline $\begin{array}{lll}\text { Cognitive } \\
\text { subtest }\end{array}$ & Components & & \\
\cline { 2 - 4 } & Verbal memory & $\begin{array}{l}\text { Attention/processing } \\
\text { speed/executive function }\end{array}$ & $\begin{array}{l}\text { Cognitive } \\
\text { flexibility }\end{array}$ \\
\hline AVLT-IR & $\mathbf{0 . 8 5 9 3 4 8}$ & 0.1786355 & -0.02420138 \\
AVLT-SR & $\mathbf{0 . 9 2 5 3 4 7}$ & 0.1656561 & 0.013152043 \\
AVLT-LR & $\mathbf{0 . 9 1 9 8 4 4}$ & 0.1586545 & 0.007458428 \\
SDMT & 0.268641 & $\mathbf{0 . 6 9 0 0 5 9 3}$ & 0.107590145 \\
DSF & 0.056095 & $\mathbf{0 . 5 3 9 1 5 9 8}$ & -0.48831854 \\
DSB & 0.256134 & $\mathbf{0 . 5 3 1 5 9 2 5}$ & -0.36294081 \\
TMT-A & 0.09689 & $\mathbf{0 . 7 9 7 0 5 3 5}$ & 0.091785669 \\
TMT-B & 0.110346 & $\mathbf{0 . 7 8 8 1 2 0 9}$ & 0.142030366 \\
LMT-IR & 0.427479 & $\mathbf{0 . 5 0 1 0 3 4 5}$ & -0.13808383 \\
SCWT-IT & 0.042578 & 0.2260081 & $\mathbf{0 . 7 5 9 7 4 8 8 9 8}$
\end{tabular}

Bold entries indicate measures with high loadings on each factor AVLT-IR Auditory Verbal Learning Test-immediate recall, AVLT-LR Auditory Verbal Learning Test-long recall, AVLT-SR Auditory Verbal Learning Test-short recall, DSB digit span backwards, DSF digit span forwards, SCWT-IT Stroop Color-Word Test Interference Trial, SDMT Symbol Digit Modalities Test, TMT Trail Making Test, LMT-IR Logical Memory Test-immediate recall
Table 3 Characteristics of cognitive domains in participants

\begin{tabular}{lllll}
\hline Cognitive domain & $\begin{array}{l}\text { Total } \\
\text { number }\end{array}$ & Mean & SD & Skew \\
\hline Memory performance & 3696 & 0.000 & 1.000 & 0.188 \\
$\begin{array}{l}\text { Attention/processing speed/executive } \\
\text { function }\end{array}$ & 3696 & 0.000 & 1.000 & -0.624 \\
$\begin{array}{l}\text { Cognitive flexibility } \\
\text { Each cognitive domain is the mean of the composite scores }\end{array}$ \\
$\begin{array}{l}\text { Skew }>0 \text {, positive skewed distribution; skew }<0 \text {, negative skewed distribution }\end{array}$
\end{tabular}

\section{Results}

Global and domain-specific cognitive performance

The means and SDs of all the cognitive tests are presented in Table 1. The PCA generated three principal components from 10 subtests with eigen values $>1$ which accounted for $64.83 \%$ of the total initial variance in cognitive test performance (Table 2). The compound scores were calculated subsequently for: 1) verbal memory; 2) attention/processing speed/executive function; and 3) cognitive flexibility. The first component, primarily comprised of immediate, short, and long recall of AVLT, was interpreted to reflect verbal memory. The second component was interpreted to reflect attention/

Table 4 Age group, education level, and cognitive performance between men and women

\begin{tabular}{llll}
\hline & $\begin{array}{l}\text { Men } \\
(n=2247)\end{array}$ & $\begin{array}{l}\text { Women } \\
(n=2326)\end{array}$ & $p$ value \\
\hline Age group (years), $n(\%)$ & & & 0.086 \\
$50-54$ & $550(24.5 \%)$ & $576(24.8 \%)$ & \\
$55-59$ & $693(30.8 \%)$ & $767(33.0 \%)$ & \\
$60-64$ & $671(29.9 \%)$ & $684(29.4 \%)$ & \\
$65-70$ & $293(13.0 \%)$ & $251(10.8 \%)$ &
\end{tabular}

Education level, $n$ (\%)

Elementary school

Junior middle school

Senior middle school

$678(30.2 \%) \quad 619(26.6 \%)$

college and above

$650(28.9 \%) \quad 293(12.6 \%)$

Global cognitive function, mean (IQR)

$\begin{array}{llll}\text { MMSE } & 29(28,30) & 26(24,28) & <0.001^{* *} \\ \text { MoCA } & 28(27,30) & 25(22,27) & <0.001^{* *}\end{array}$

Domain-specific cognitive function, mean (IQR)

$\begin{array}{llll}\text { Verbal memory } & -0.10 & 0.03(-0.68, & 0.003^{*} \\ & (-0.73,0.64) & 0.73) & \\ \text { Attention/processing speed/ } & 0.29(-0.38, & -0.03 & <0.001^{* *} \\ \text { executive function } & 0.77) & (-0.83,0.59) & \\ \text { Cognitive flexibility } & -0.08 & 0.12\left(-0.39,<0.001^{* *}\right. \\ & (-0.63,0.39) & 0.67) & \end{array}$

Data shown as $n(\%)$ were compared between two groups using the chi-square test

Data with skewed distribution shown as median (interquartile range (IQR)) were compared between two groups using the Mann Whitney $U$ test MMSE Mini-Mental State Examination, MoCA Montreal Cognitive Assessment $* P<0.05 ; * * P<0.001$ 


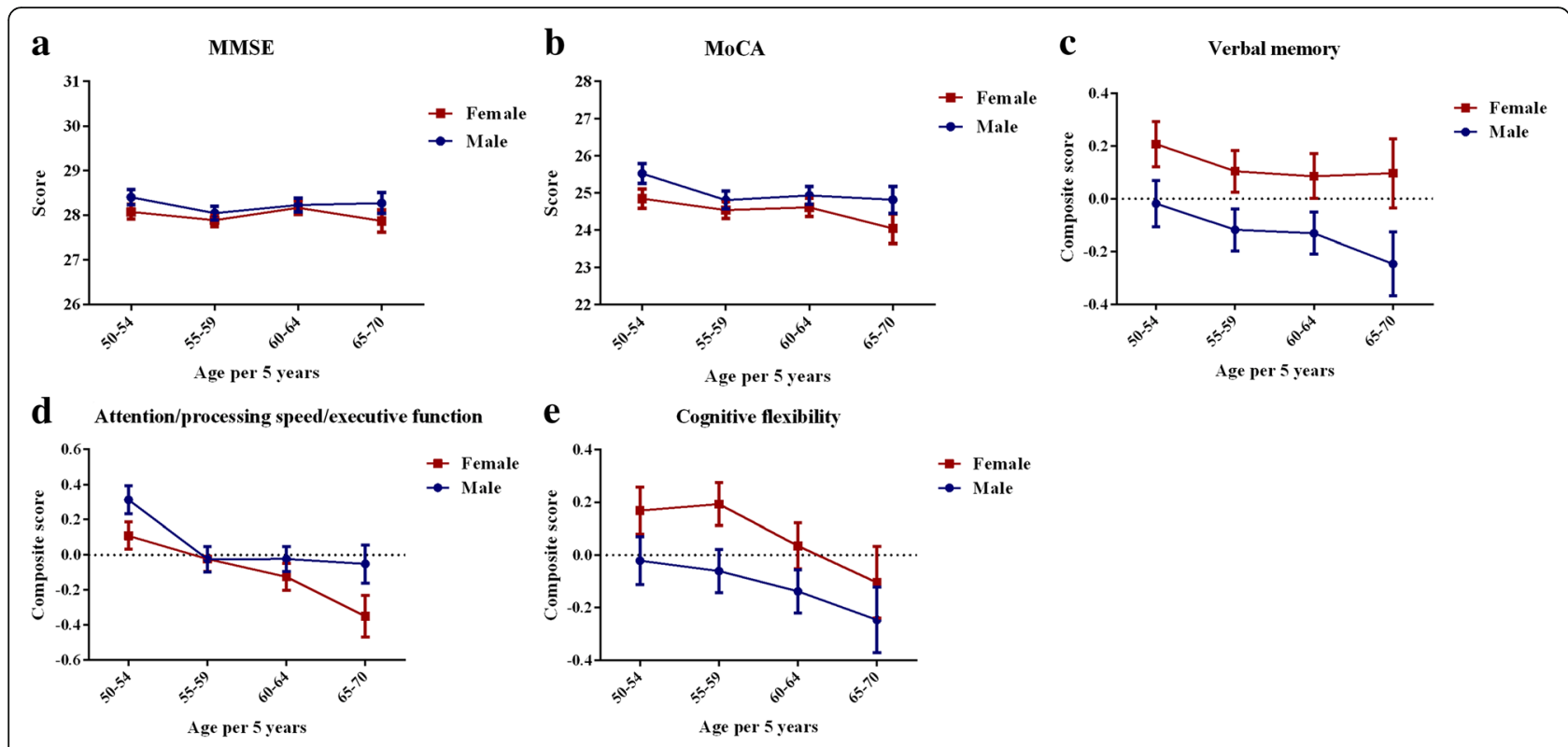

Fig. 2 Gender-specific age effects on a Mini-Mental State Examination (MMSE), b Montreal Cognitive Assessment Test (MoCA), c verbal memory, $\mathbf{d}$ attention/processing speed/executive function, and e cognitive flexibility. The $x$ axis represents age in 5-year groups and the $y$ axis represents the scores. Error bars represent 95\% confidence intervals. Estimates are adjusted for level of education

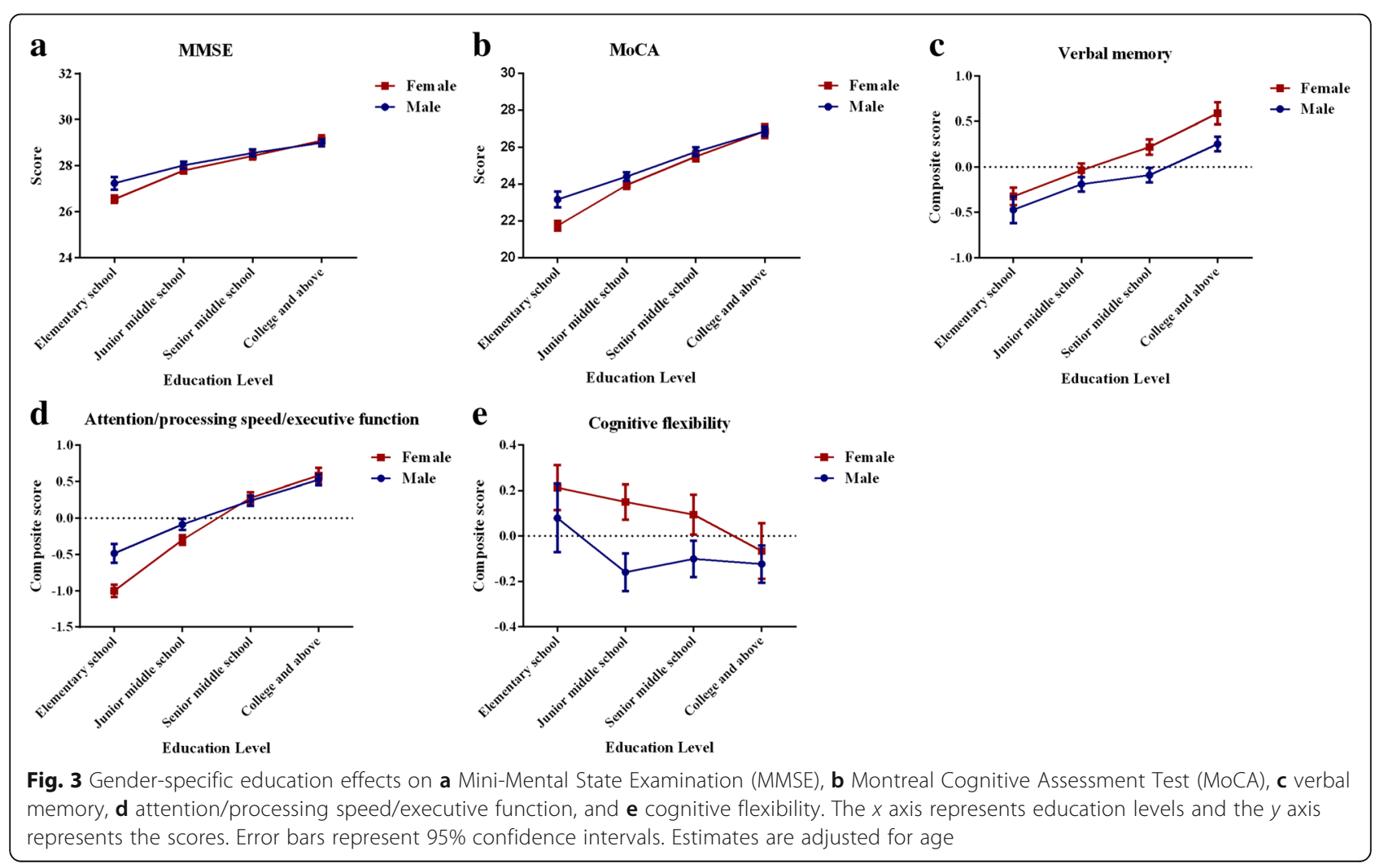


Table 5 General characteristics of the participants

\begin{tabular}{|c|c|c|c|}
\hline & Men & Women & $p$ value \\
\hline Number, $n(\%)$ & 2247 (49.1\%) & $2326(50.9 \%)$ & - \\
\hline \multicolumn{4}{|l|}{ Sociodemographic characteristics } \\
\hline Age (years), median (IQR) & $59(55,62)$ & $58(54,62)$ & $0.045^{*}$ \\
\hline Education (years), median (IQR) & $12(9,15)$ & $9(9,12)$ & $<0.001^{* *}$ \\
\hline Occupation, $n$ (\%) & & & $<0.001^{* *}$ \\
\hline Manual work & $452(20.1 \%)$ & $723(31.1 \%)$ & \\
\hline White-collar work & $921(41.0 \%)$ & $453(19.5 \%)$ & \\
\hline Monthly income, $n(\%)$ & & & $<0.001^{* *}$ \\
\hline Low & $607(27.0 \%)$ & $868(37.3 \%)$ & \\
\hline Medium & $734(32.7 \%)$ & $722(31.1 \%)$ & \\
\hline High & $906(40.3 \%)$ & $736(31.6 \%)$ & \\
\hline BMI $\left(\mathrm{kg} / \mathrm{m}^{2}\right)$, mean $\pm \mathrm{SD}$ & $25.38 \pm 3.12$ & $24.59 \pm 3.16$ & $<0.001^{* *}$ \\
\hline BMI group, $n(\%)$ & & & $<0.001^{* *}$ \\
\hline Underweight & $19(0.8 \%)$ & $27(1.16 \%)$ & \\
\hline Normal weight & $992(44.1 \%)$ & $1268(54.5 \%)$ & \\
\hline Overweight & $1018(45.3 \%)$ & $805(34.6 \%)$ & \\
\hline Obese & $218(9.7 \%)$ & $226(9.7 \%)$ & \\
\hline \multicolumn{4}{|l|}{ Lifestyle, $n(\%)$} \\
\hline Solitude & $42(1.9 \%)$ & $45(1.9 \%)$ & 0.871 \\
\hline Reading habits & $1450(64.5 \%)$ & $1125(48.4 \%)$ & $<0.001^{* *}$ \\
\hline Physically active & $1612(71.7 \%)$ & $1712(73.6 \%)$ & 0.158 \\
\hline Current smoker & $973(43.3 \%)$ & $62(2.7 \%)$ & $<0.001^{* *}$ \\
\hline Current drinker & $1123(50.0 \%)$ & 127 (5.5\%) & $<0.001^{* *}$ \\
\hline \multicolumn{4}{|l|}{ Medical history, n (\%) } \\
\hline Diabetes & $372(16.6 \%)$ & $281(12.1 \%)$ & $<0.001^{* *}$ \\
\hline Hypertension & $784(34.9 \%)$ & $664(28.5 \%)$ & $<0.001^{* *}$ \\
\hline Hyperlipidemia & $476(21.2 \%)$ & $494(21.2 \%)$ & 0.964 \\
\hline Stroke & $32(1.4 \%)$ & $26(1.1 \%)$ & 0.355 \\
\hline Coronary heart disease & $203(9.0 \%)$ & $140(6.0 \%)$ & $<0.001^{* *}$ \\
\hline Family history of dementia & $160(7.1 \%)$ & $204(8.8 \%)$ & $0.039 *$ \\
\hline
\end{tabular}

Data shown as median (interquartile range (IQR)) were compared between two groups using the Mann Whitney $U$ test

Data shown as mean \pm standard deviation (SD) were compared between two groups using the Student $t$ test

Data shown as $n(\%)$ were compared between two groups using the chi-square test

$B M I$ body mass index

$* P<0.05 ; * * P<0.001$

processing speed/executive function, with SDMT, LMT-IR, TMT A and B, DSF, and DSB contributing substantially. The third component was interpreted with SCWT-IT to reflect cognitive flexibility. The means and SDs of the composite scores of the three specific domains used in the analyses are presented in Table 3. All the cognitive tests had skewed distribution and the specific domains were symmetric.

\section{Gender-specific cognitive patterns}

Women scored better than men on verbal memory and cognitive flexibility, whereas men scored better on the
MMSE, MoCA, and attention/processing speed/executive function (Table 4).

The gender-specific cognitive patterns are presented in Figs. 2 and 3, which show mean levels and 95\% confidence intervals (CIs) of cognitive performance stratified by age or education. On one hand, the female cognitive advantage across all ages was significant for verbal memory performance. Age was significantly associated with each cognitive measure in both men and women. On the other hand, a significant gender discrepancy existed for education level, and women tended to be less educated. In the elementary school educated group, women 


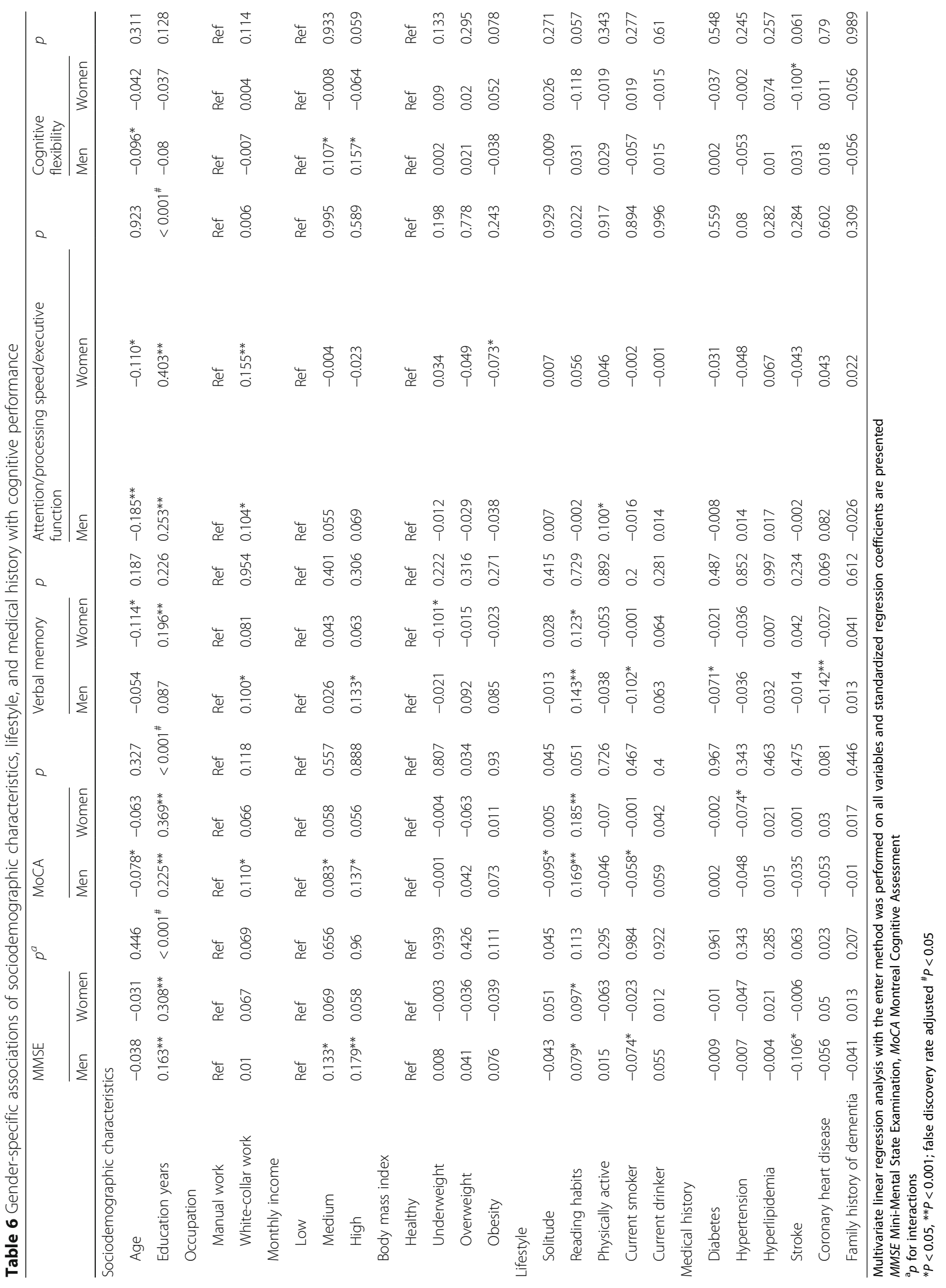


Table 7 Proportion of variance accounted for cognitive performance in linear regression analyses for 12 cognitive tests

\begin{tabular}{llll}
\hline Cognitive tests & Model 1 & Model 2 & $\Delta R^{2}$ \\
\hline MMSE & 0.150 & 0.176 & 0.026 \\
MoCA & 0.255 & 0.314 & 0.059 \\
AVLT-IR & 0.124 & 0.161 & 0.037 \\
AVLT-SR & 0.118 & 0.16 & 0.042 \\
AVLT-LR & 0.118 & 0.168 & 0.050 \\
SDMT & 0.279 & 0.304 & 0.025 \\
DSF & 0.084 & 0.108 & 0.024 \\
DSB & 0.140 & 0.159 & 0.019 \\
TMT-A & 0.214 & 0.232 & 0.018 \\
TMT-B & 0.172 & 0.193 & 0.021 \\
LMT-IR & 0.201 & 0.242 & 0.041 \\
SCWT-IT & 0.016 & 0.018 & 0.002 \\
\hline
\end{tabular}

The values represent the proportion of variance $\left(R^{2}\right)$ in the regression model In model 1, the linear regression analysis was performed only on age, gender, and education

In model 2, the linear regression analysis was performed on all the sociodemographic, lifestyle, and medical variables

Both models used the enter method

AVLT-IR Auditory Verbal Learning Test-immediate recall, AVLT-LR Auditory Verbal Learning Test-long recall, AVLT-SR Auditory Verbal Learning Test-short recall, DSB digit span backwards, DSF digit span forwards, MMSE Mini-Mental State Examination, MoCA Montreal Cognitive Assessment, SCWT-IT Stroop Color-Word Test Interference Trial, SDMT Symbol Digit Modalities Test, TMT Trail Making Test, LMT-IR Logical Memory Test-immediate recall

performed significantly worse than men in MMSE, MoCA, and attention/processing speed/executive function. However, this difference was eliminated in those with a higher education. In the senior middle school and college and above educated group, women performed the same as men in the aforementioned cognitive performance and even better than men for verbal memory. With respect to cognitive flexibility, women achieved significantly higher scores than men only for junior and senior middle school education.

\section{Gender-specific risk factors for cognitive performance}

The comparison of sociodemographic characteristics, lifestyle, and medical variables between men and women are provided in Table 5. Compared with men, women included in our analysis were slightly younger $(p=0.04)$ and less likely to be engaged in white-collar work $(p<$ $0.001)$. Women also reported lower education $(p<0.001)$ and income $(p<0.001)$. Meanwhile, a higher prevalence of being overweight and a lower prevalence of underweight body mass index (BMI) was observed in men compared with women $(p<0.001)$. With regard to lifestyle, men were more likely than women to be current smokers $(p<0.001)$ and to report current alcohol use and reading habits $(p<0.001)$. Differences in disease prevalence were such that men were more likely than women to report diabetes $(p<0.001)$, hypertension $(p<0.001)$, and coronary heart disease $(p<0.001)$, whereas women were more likely to have a family history of dementia $(p=0.039)$.

We examined the gender-specific risk factors on cognitive performance using multivariate analysis (Table 6) and found that sociodemographic, lifestyle, and medical variables had different effects on cognitive performance in men and women. For sociodemographic characteristics, male global and domain-specific cognitive performance was positively associated with education, intellectual occupation, and higher monthly income, whereas it was negatively associated with age. Similarly, female cognitive performance was also positively associated with education and a white-collar occupation and negatively associated with age. Furthermore, being underweight and obesity also negatively impacted female verbal memory and attention/processing speed/executive function. For lifestyle, both male and female global cognitive performance and verbal memory benefited from reading habits. Meanwhile, solitude and smoking were negatively associated with male global cognitive score and verbal memory while being physically active had a positive influence on male attention/processing speed/executive function. For medical variables, diabetes and coronary heart disease were associated with lower verbal memory score in men, hypertension was associated with lower MoCA scores in women, and stroke was associated with a lower MMSE score in men and cognitive flexibility score in women. Significant differences between men and women were observed for an association of years of education with MMSE, MoCA, and attention/processing speed/executive function. The effects of increased education years on general cognition and attention/processing speed/ executive function were significantly greater in women than men $(p<0.001$ for interaction, and $p<0.05$ after FDR adjustment).

\section{Development of normative data for 12 cognitive tests and related $z$ score}

The predictive scores and normative data were developed based on three variables of age, gender, and education from multivariate regression models (Table 7). The equations are shown in Additional file 1 and the regression coefficients are presented in Table 8 . Next, the predictive scores were used to generate demographically adjusted $z$ scores which can be converted to a percentile that indicates the individual's cognitive performance among peers of comparable age, gender, and education. The normative data of 12 cognitive tests were determined and stratified by age, gender, and education (Table 9, Fig. 4a-1). Furthermore, the reference 


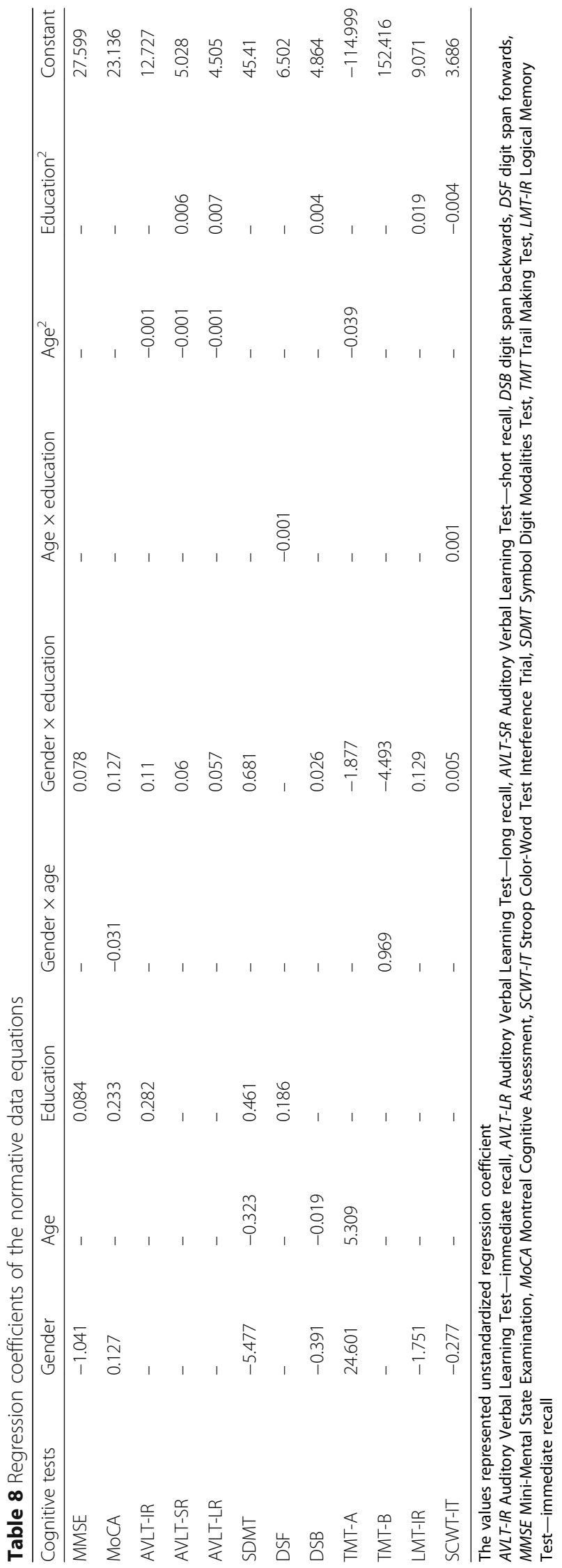




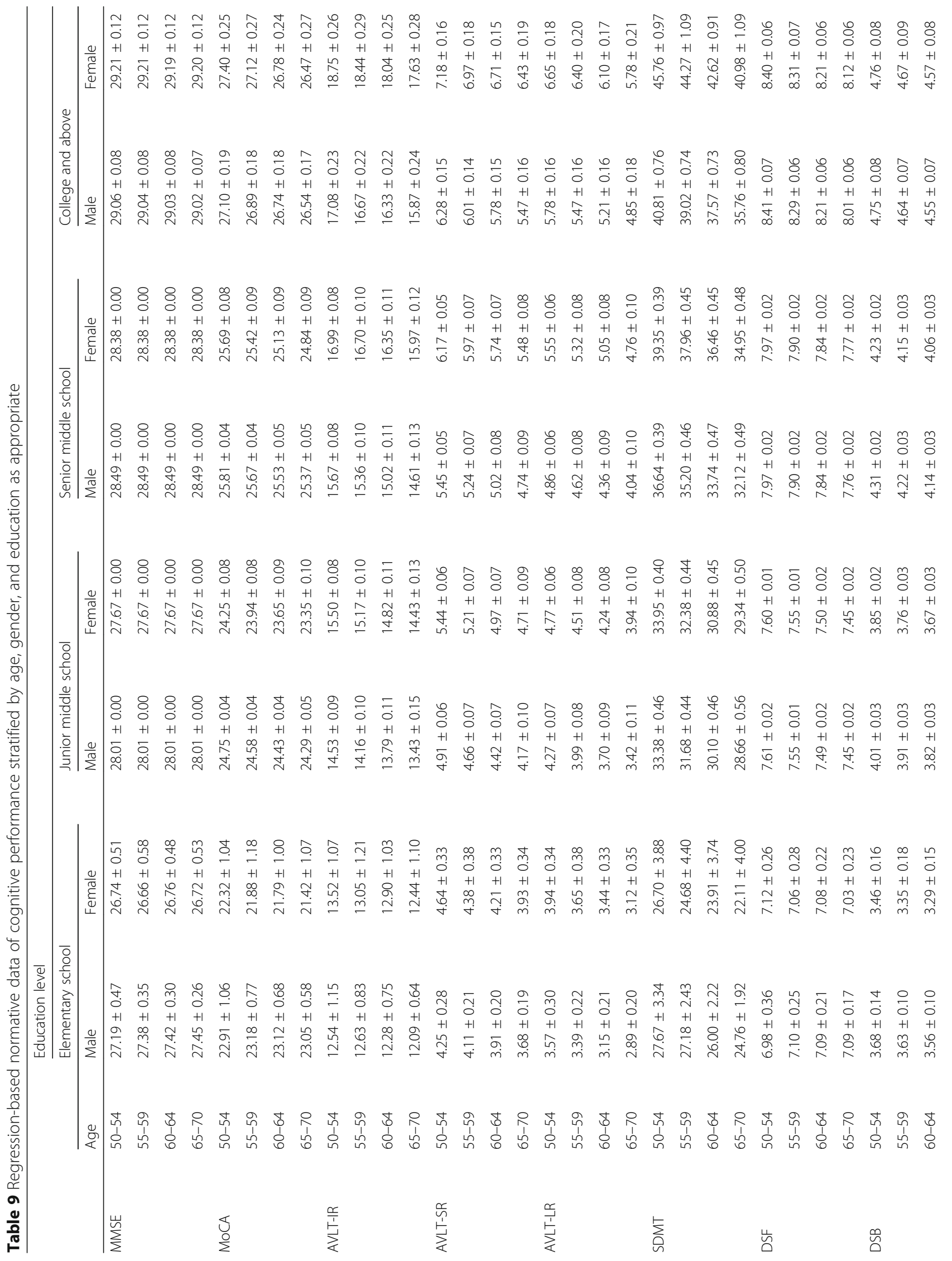




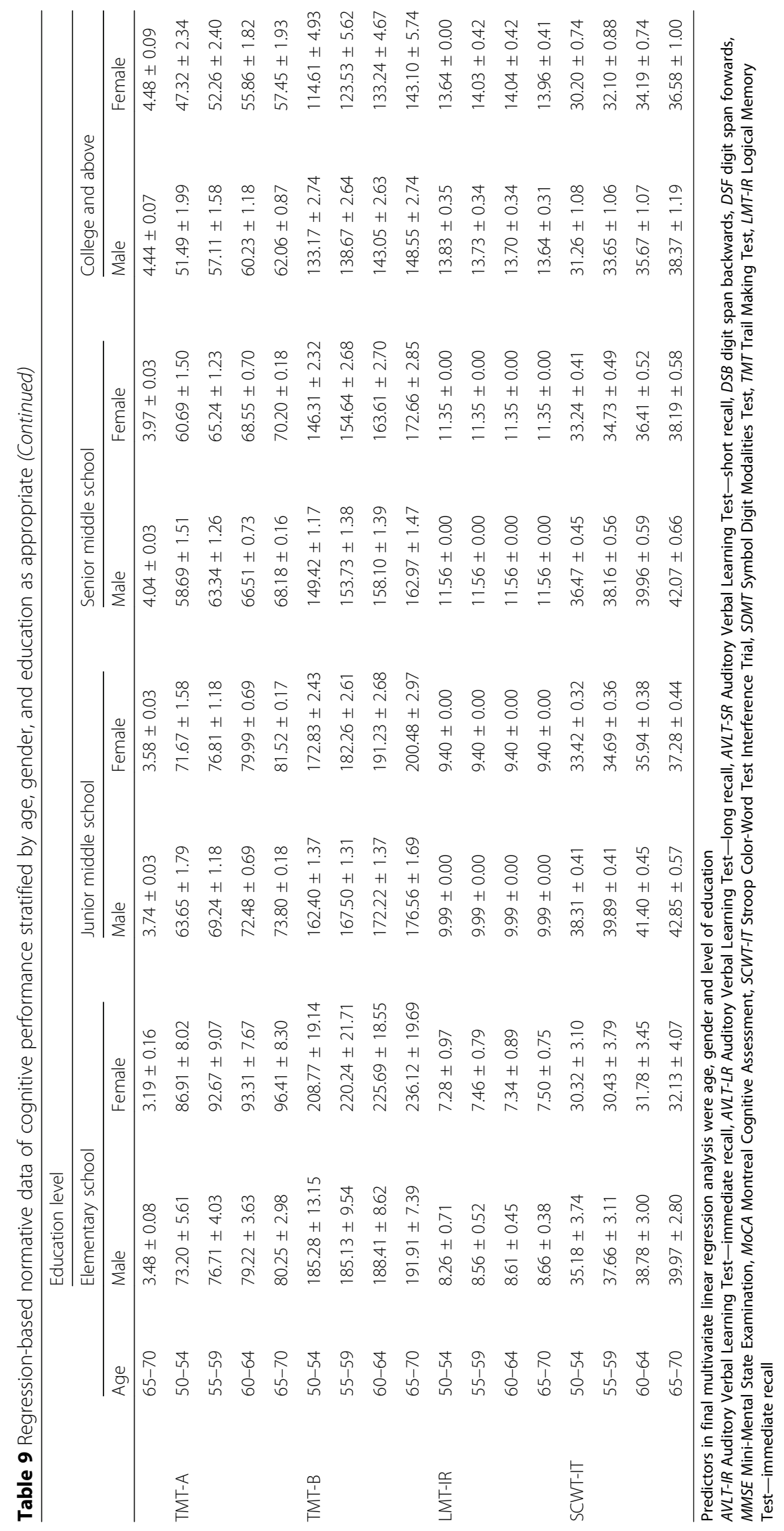




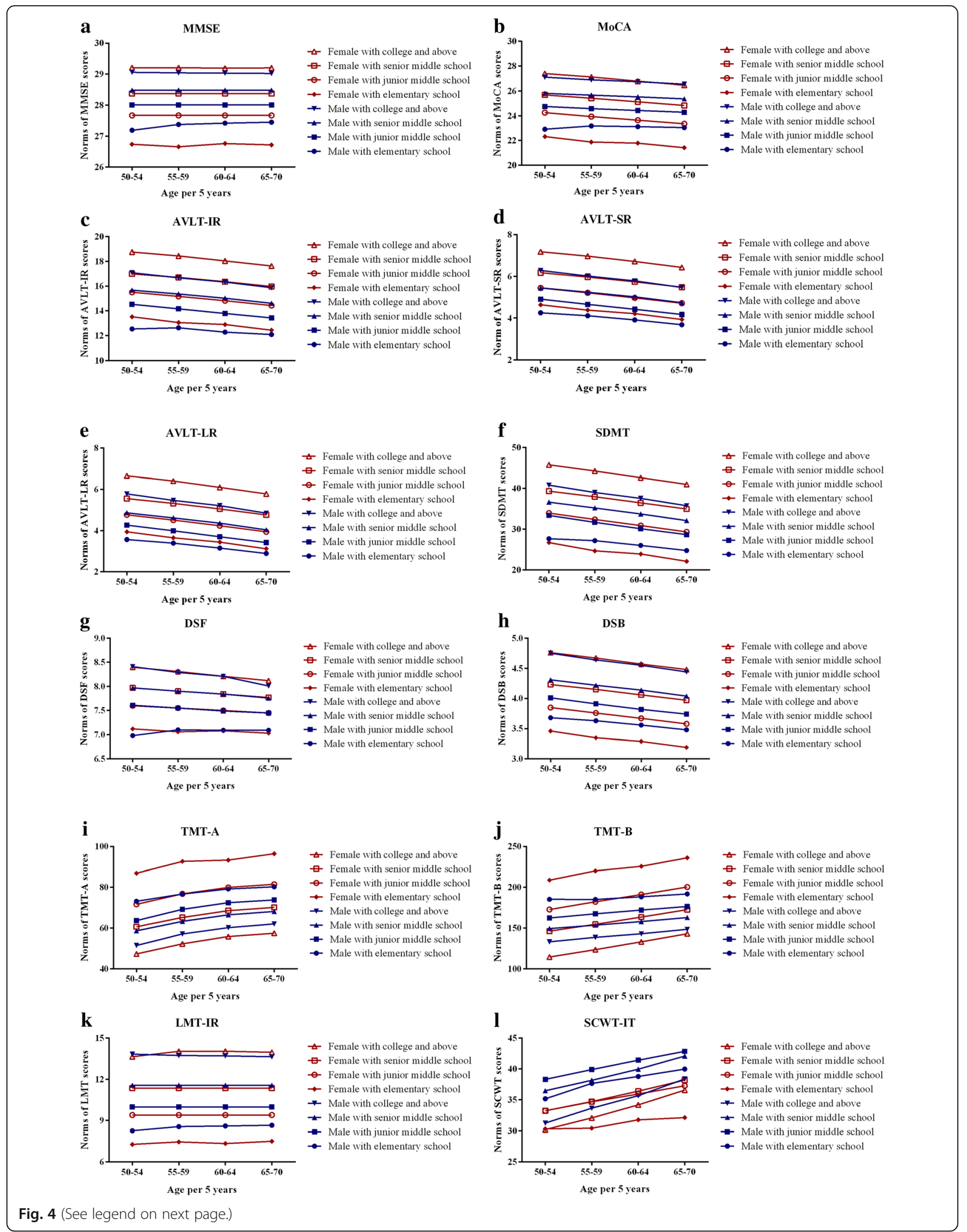


(See figure on previous page.)

Fig. 4 Gender-, age-, and education-adjusted norms of (a) Mini-Mental State Examination (MMSE), (b) Montreal Cognitive Assessment Test (MoCA), (c) Auditory Verbal Learning Test-immediate recall (AVLT-IR), and (d) Auditory Verbal Learning Test—-short recall (AVLT-SR). Gender-, age--, and education-adjusted norms of (e) Auditory Verbal Learning Test-long recall (AVLT-LR), (f) Symbol Digit Modalities Test (SDMT), (g) Digit span forwards (DSF), and (h) Digit span backwards (DSB). Gender-, age-, and education-adjusted norms of (i) Trail Making Test (TMT)-A, (j) TMT-B, (k) Logical Memory Test-immediate recall (LMT-IR), and (I) Stroop Color-Word Test Interference Trial (SCWT-IT)

cut-off values are also shown (Table 10) to define cognitive impairment.

\section{Discussion}

This large community-based study in three Chinese areas is among the first to: 1) examine gender-specific cognitive patterns; 2) explore the gender-specific risk and protective factors; and 3) establish age-, gender-, and education-specific normative data for 12 cognitive tests among a Chinese middle-aged and elderly population. Prior studies mostly employed single or limited cognitive measures and smaller samples to establish restricted normative data [27-29]. Consequently, they may not capture the wide range of cognitive function needed to reflect early changes in mid-life with gender-specific initial ability levels. Thus, encompassing and comparing a wide spectrum of cognitive function may be particularly valuable in identifying modifiable risk factors and critical periods of cognitive impairment following mid-life.

\section{Gender-specific cognitive patterns}

An increasing number of studies carried out in Chinese populations have shown gender-specific cognitive patterns both in China and abroad [30-33]. The rate of global cognitive decline was faster among females than males according to MMSE [30]. In agreement with the Rotterdam Study [34], our study also did not find a rapid change in MMSE score until the age of 70 years which suggests an increased need to pay more attention to a wider range of cognitive domains since the global cognition may be stable before the age of 70 years.

Significant gender disparities were observed in three cognitive domains across different age and education groups. With respect to verbal memory, our results were partially congruent with a growing literature that suggest women perform better than men [35-38]. Interestingly, it has been reported that a female advantage in verbal memory remains consistent throughout the lifespan. Furthermore, a 10-year cohort study found that women outperformed men not only on verbal memory, but also on verbal recognition and semantic fluency tasks [39], suggesting that the female advantage for verbal memory tasks is possibly because women are inclined to use semantic clustering in recall. Contrary to verbal memory, men tended to score higher than women for attention/ processing speed/executive function, which is an important cognitive capacity to attend to or to "stay on" a task [40] to complete a task quickly and accurately under the cognitive control of behavior. However, the results only showed the male advantage in the 50-54 and 65-70 years age groups, consistent with previous reports that age-related associations for processing speed were stronger than other domains [41]. The SCWT-IT was interpreted to reflect cognitive flexibility. Van der Elst et al. [42] found clear gender differences on the Stroop interference scores. Nevertheless, the results of regression analyses showed that the influence of age, gender, and education was less profound, which indicated that deficits in Stroop tests may be influenced by intricate factors with concurrent effects.

\section{Gender-specific risk factors for cognitive performance}

Studying gender differences in cognitive function is a complex and controversial topic. Furthermore, the relevance of biological and environmental factors is not yet clear. Given the gaps in our knowledge of the genderspecific associations between these factors and cognition in previous studies, our results may be of special importance.

The effects of education on women were more substantial than in men for general cognition and attention/ processing speed/executive function. As we can see from Fig. 3, education could reverse the inferiority in women and even lead to superiority in performance of global and domain-specific cognitive performance. Education may explain most of the gender disparity in cognitive pattern, which was also indicated by Lei et al. from China [31] and Lee et al. from India [43]. With respect to verbal memory, we may presume that education could strengthen the semantic clustering in recall. For attention/processing speed/executive function, the Chinese have a larger male advantage in this domain than Americans, with a potential reason being the relatively equivalent access to formal education in developed countries [40]. In former low-income environments, such as traditional rural China, families may favor sons and large gender gaps in schooling exist in low-income settings. Such long-term educational attainment disparities that Chinese women experience through their life course may affect their cognitive trajectory.

Asides from education, a large range of potentially reversible risk factors for cognitive performance were identified and show gender differences, notably white-collar 
Table 10 Age-, gender-, and education-specific reference values for cognitive tests

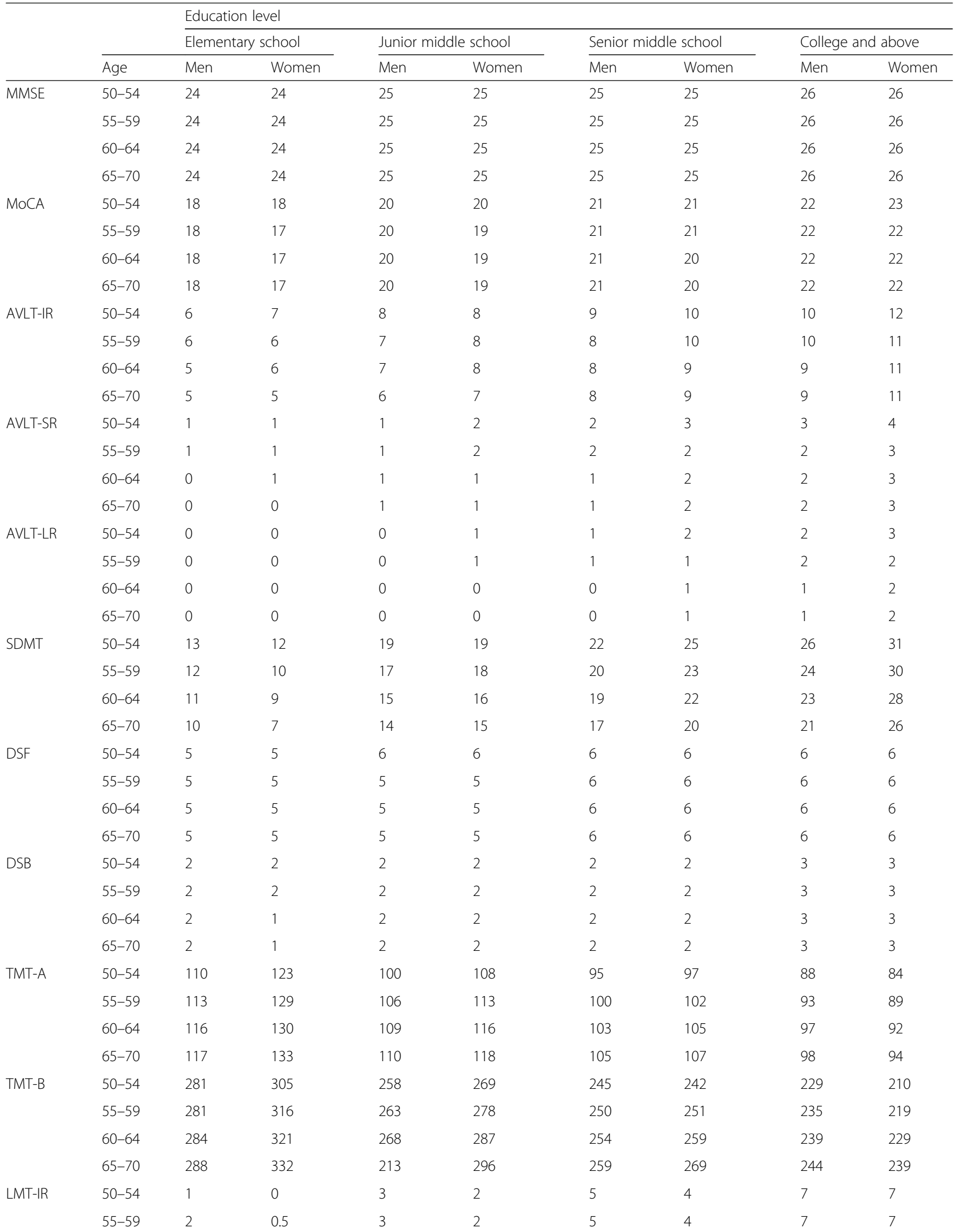


Table 10 Age-, gender-, and education-specific reference values for cognitive tests (Continued)

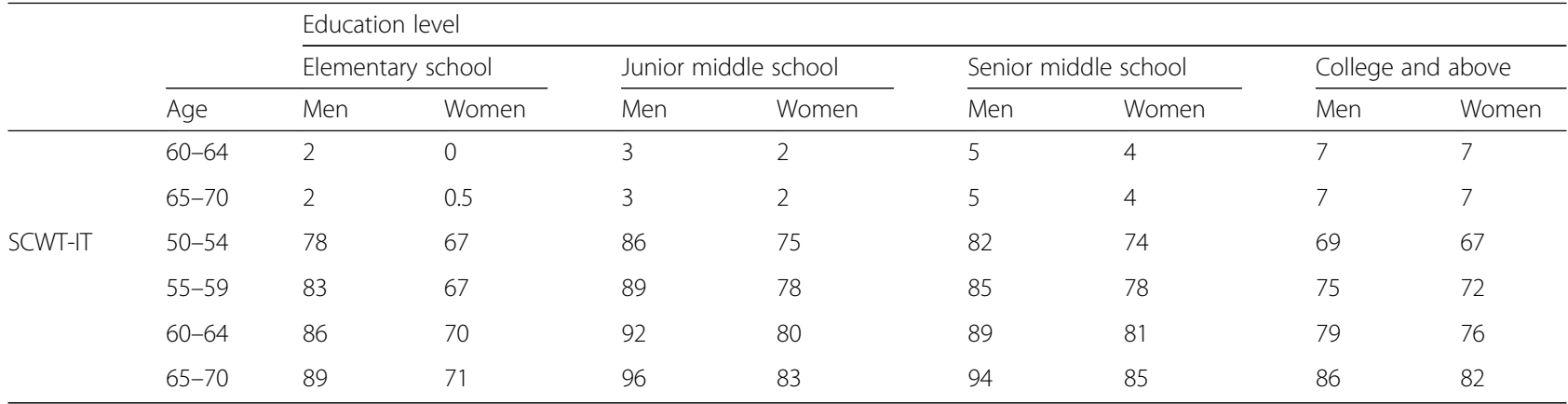

Age-, gender-, and education-specific reference values were defined as 1.5 times root mean square error (RMSE) under the mean of normative score for MMSE, MoCA, AVLT-IR, AVLT-SR, AVLT-LR, SDMT, DSF, DSB, and LMT-IR, and 1.5 times RMSE above the mean of normative score for TMT-A, TMT-B, and SCWT-IT

$A V L T$-IR Auditory Verbal Learning Test-immediate recall, AVLT-LR Auditory Verbal Learning Test-long recall, AVLT-SR Auditory Verbal Learning Test-short recall, DSB digit span backwards, DSF digit span forwards, MMSE Mini-Mental State Examination, MoCA Montreal Cognitive Assessment, SCWT-IT Stroop Color-Word Test Interference Trial, SDMT Symbol Digit Modalities Test, TMT Trail Making Test, LMT-IR Logical Memory Test-immediate recall

work, a higher income level, smoking, diabetes, and coronary heart disease for men, and underweight and obesity as well as hypertension for women. Although no significant between-gender differences were observed, the subgroup analysis also indicated that these risk factors should be taken into consideration in the development of gender-specific preventive intervention programs for cognition.

\section{The need for normative data and a comparison with normative scores}

Finally in this study, we provided demographically adjusted and regression-based normative data for 12 cognitive tests. The overall sample size in our study was large and excluded cognitive disorders. The normative data and reference values are finely stratified by the most relevant demographic factors. A quick, efficient, and straightforward method to obtain $z$ scores and percentile rank estimates for specific participants is also provided for clinical researchers.

Normative data have been shown to be indispensable for distinguishing normal aging from early transition to cognitive impairment. Undoubtedly, it would be better to endorse age-, gender-, or education-specific cut-off scores based on demographically adjusted normative data in research. As a result, researchers have tried to yield better screening accuracy instead of uniform cut-off scores [44, 45]. Differences are noted when compared with prior studies for normative scores in the Chinese $[46,47]$. These differences are likely attributed to distinction in reporting of the normative data. The present study employed a regression-based approach instead of typical methods (e.g., means and SDs calculated from raw scores). The problem intrinsically related to the latter is the need for a relatively smaller size of subgroups [48]. In the regression-based approach, norms are derived from equations by using the data for all the samples and the abovementioned problem disappears with no need for a subdivided sample. Also, the unbalanced data will not affect the norms in the regressionbased approach because the estimation of the regression weights cannot be biased by any imbalance in the sample but only results in some loss of statistical power [49]. Furthermore, normative data and an estimated $z$ score (and ultimately percentile rank) can even be obtained for particular participants with certain demographic characteristics out of the sample [50].

Certain limitations of this study are noted. First, the present cross-sectional study reported "conventional" norms based on exclusion of participants with evident clinical neurodegenerative diseases instead of "robust" norms that follow individuals longitudinally. It further excludes individuals with subclinical/latent neurological diseases, which may provide less appropriate norms and decreased sensitivity to mild deficits [51], although some research has suggested similarities between two norms in identifying early cognitive impairment [52]. Second, the present study did not take the residential area into consideration, such as a differentiation between urban and rural regions, which may contribute to local differences in education, occupational experiences, income, and lifestyle over the lifespan. Third, since all the medical variables were self-reported, participants may underestimate their symptoms or hesitate to report their real medical status to avoid being perceived as complainers.

\section{Conclusions}

In summary, this study holds significance as it contributes to the ongoing investigation of gender-specific cognitive patterns and predictors of cognitive performance among middle-aged and elderly Chinese. Males were inclined to outperform females in global cognition and attention/processing speed/executive function, while 
females tended to do better on verbal memory as well as cognitive flexibility. These cognitive disparities were considerably mitigated or even reversed but not fully explained by education. Meanwhile, the regression-based and demographically adjusted normative score was provided for 12 cognitive tests to serve as an additional resource and guidance for clinical researchers. Taken together, our findings call for future longitudinal follow-up to improve our knowledge of cognitive patterns and related risk factors. We believe that better understanding the biology of gender differences in cognitive patterns will not only be conducive to advocating a healthy lifestyle and promoting gender-specific interventions to prevent or minimize cognitive impairment but will also be integral to the investigation of personalized, genderspecific new therapies.

\section{Additional file}

Additional file 1: Supplementary methods and results. (DOCX 34 kb)

\section{Abbreviations}

AD: Alzheimer's disease; ADI: Alzheimer's Disease International; AVLT: Auditory Verbal Learning Test; AVLT-IR: Auditory Verbal Learning Test-immediate recall; AVLT-LR: Auditory Verbal Learning Test-long recall; AVLT-SR: Auditory Verbal Learning Test—short recall; BMI: Body mass index; DSB: Digit span backwards; DSF: Digit span forwards; EMCOA: Effects and Mechanism of Cholesterol and Oxysterol on Alzheimer's disease; FDR: False discovery rate; LMT-IR: Logical Memory Test_-immediate recall; $\mathrm{MCl}$ : Mild cognitive impairment; MMSE: Mini-Mental State Examination; MoCA: Montreal Cognitive Assessment Test; PCA: Principal component analysis; SCWT-IT: Stroop Color-Word Test Interference Trial; SD: Standard deviation; SDMT: Symbol Digit Modalities Test; TMT: Trail Making Test; WMSRC: Wechsler Memory Scale Revised for China

\section{Acknowledgements}

The authors are indebted to Deqiang Zheng, Dian He, and Yanxia Luo from the Department of Epidemiology and Health Statistics of Capital Medical University for their statistical advice. The authors also thank Hongguo Rong, Junfang Zhao, and the medical and ancillary staff of the Health Examination Center in Linyi and Jincheng and Beijing Chaoyang District Center for Disease Control and Prevention for assistance in the field survey. They also thank all participants for their time.

\section{Funding}

This work was supported by the State Key Program of the National Natural Science Foundation of China (grant no. 81330065) and National Natural Science Foundation of China (grant no. 81673149).

\section{Availability of data and materials}

The datasets during and/or analyzed during the current study are available from the corresponding author on reasonable request.

\section{Authors' contributions}

RX conceptualized and designed the study, obtained funding, and supervised data collection. YA and LF conducted the data analysis, and drafted and critically revised the manuscript. XZ, YiW, YuW, LT, YL, and ZQ made substantial contributions to the acquisition of data, and analysis and interpretation of data. All authors read and approved the final manuscript.

\section{Ethics approval and consent to participate}

The study design was ethically approved by the Ethics Committee of Capital Medical University (2013SY35). All participants provided written informed consent at the beginning of the study.

\section{Consent for publication}

All the co-authors and participants have given their consent for publication.

\section{Competing interests}

The authors declare that they have no competing interests.

\section{Publisher's Note}

Springer Nature remains neutral with regard to jurisdictional claims in published maps and institutional affiliations.

\section{Author details}

${ }^{1}$ School of Public Health, Capital Medical University, No.10 Xitoutiao, You An Men Wai, Beijing 100069, China. ${ }^{2}$ Peking university First Hospital, Beijing, China. ${ }^{3}$ Linyi Mental Health Center, Linyi, Shandong, China. ${ }^{4}$ Jincheng People's Hospital, Jincheng, Shanxi, China.

Received: 17 March 2018 Accepted: 14 August 2018

Published online: 15 September 2018

\section{References}

1. Prince M, Wimo A, Guerchet M, Ali G, Wu Y, Prina M. World Alzheimer Report 2015. The global impact of dementia. An analysis of prevalence, incidence, cost \& trends. London: Alzheimer's Disease International (ADI); 2015.

2. Albert MS. Changes in cognition. Neurobiol Aging. 2011;32(Suppl 1):S58-63.

3. Tariq S, Barber PA. Dementia risk and prevention by targeting modifiable vascular risk factors. J Neurochem. 2017;144(5):565-81.

4. Prince M, Bryce R, Albanese E, Wimo A, Ribeiro W, Ferri CP. The global prevalence of dementia: a systematic review and metaanalysis. Alzheimers Dement. 2013;9(1):63-75.

5. Paulo AC, Sampaio A, Santos NC, Costa PS, Cunha P, Zihl J, Cerqueira J, Palha JA, Sousa N. Patterns of cognitive performance in healthy ageing in northern Portugal: a cross-sectional analysis. PLoS One. 2011;6(9):e24553.

6. Bergman I, Almkvist O. Neuropsychological test norms controlled for physical health: does it matter? Scand J Psychol. 2015;56(2):140-50.

7. Xu W, Tan L, Wang HF, Jiang T, Tan MS, Tan L, Zhao QF, Li JQ, Wang J, Yu JT. Meta-analysis of modifiable risk factors for Alzheimer's disease. J Neurol Neurosurg Psychiatry. 2015;86(12):1299-306.

8. Kesse-Guyot E, Andreeva VA, Lassale C, Hercberg S, Galan P. Clustering of midlife lifestyle behaviors and subsequent cognitive function: a longitudinal study. Am J Public Health. 2014;104(11):e170-7.

9. Bennett DA, Arnold SE, Valenzuela MJ, Brayne C, Schneider JA. Cognitive and social lifestyle: links with neuropathology and cognition in late life. Acta Neuropathol. 2014;127(1):137-50.

10. Lu Y, An Y, Yu H, Che F, Zhang X, Rong H, Xi Y, Xiao R. Sex-specific nonlinear associations between serum lipids and different domains of cognitive function in middle to older age individuals. Metab Brain Dis. 2017; 32(4):1089-97

11. Lu Y, An Y, Guo J, Zhang X, Wang H, Rong H, Xiao R. Dietary intake of nutrients and lifestyle affect the risk of mild cognitive impairment in the Chinese elderly population: a cross-sectional study. Front Behav Neurosci. 2016;10:229.

12. Johnson DK, Storandt M, Morris JC, Galvin JE. Longitudinal study of the transition from healthy aging to Alzheimer disease. Arch Neurol. 2009; 66(10):1254-9.

13. Hedden T, Oh H, Younger AP, Patel TA. Meta-analysis of amyloid-cognition relations in cognitively normal older adults. NEUROLOGY. 2013;80(14): 1341-8.

14. Bennett DA, Wilson RS, Schneider JA, Evans DA, Beckett LA, Aggarwal NT, Barnes LL, Fox JH, Bach J. Natural history of mild cognitive impairment in older persons. Neurology. 2002;59(2):198-205.

15. Larouche E, Tremblay MP, Potvin O, Laforest S, Bergeron D, Laforce R, Monetta L, Boucher L, Tremblay P, Belleville S, et al. Normative data for the Montreal cognitive assessment in middle-aged and elderly Quebec-French people. Arch Clin Neuropsychol. 2016; https://doi.org/10.1093/arclin/acw076.

16. Schneider AL, Sharrett AR, Gottesman RF, Coresh J, Coker L, Wruck L, Selnes OA, Deal J, Knopman D, Mosley TH. Normative data for 8 neuropsychological tests in older blacks and whites from the atherosclerosis risk in communities (ARIC) study. Alzheimer Dis Assoc Disord. 2015;29(1):32-44.

17. Migdanis I, Gioulbasanis I, Lianou E, Migdanis A, Kanaki M, Kiriakou Gl, Sgantzos M, Kapsoritakis A, Kontogianni M. Nutritional status and 
objective assessment of functional status in patients with neoplastic diseases receiving antineoplastic therapy: preliminary results. Clin Nutr ESPEN. 2018;24:186

18. Folstein MF, Folstein SE, McHugh PR. "Mini-mental state". A practical method for grading the cognitive state of patients for the clinician. J Psychiatr Res. 1975;12(3):189-98.

19. Nasreddine ZS, Phillips NA, Bedirian V, Charbonneau S, Whitehead V, Collin I, Cummings $J$, Chertkow $\mathrm{H}$. The Montreal cognitive assessment, MoCA: a brief screening tool for mild cognitive impairment. J Am Geriatr Soc. 2005; 53(4):695-9.

20. Ma J, Zhang Y, Guo Q. Comparison of vascular cognitive impairment-no dementia by multiple classification methods. Int J Neurosci. 2015;125(11): 823-30.

21. Price $K L$, DeSantis SM, Simpson AN, Tolliver BK, McRae-Clark AL, Saladin ME, Baker NL, Wagner MT, Brady KT. The impact of clinical and demographic variables on cognitive performance in methamphetamine-dependent individuals in rural South Carolina. Am J Addict. 2011:20(5):447-55.

22. Wang C, An Y, Yu H, Feng L, Liu Q, Lu Y, Wang H, Xiao R. Association between exposure to the Chinese famine in different stages of early life and decline in cognitive functioning in adulthood. Front Behav Neurosci. 2016;10:146

23. Miu J, Negin J, Salinas-Rodriguez A, Manrique-Espinoza B, Sosa-Ortiz AL, Cumming R, Kowal P. Factors associated with cognitive function in older adults in Mexico. Glob Health Action. 2016;9:30747.

24. Wei M, Shi J, Li T, Ni J, Zhang X, Li Y, Kang S, Ma F, Xie H, Qin B, et al. Diagnostic accuracy of the Chinese version of the trail-making test for screening cognitive impairment. J Am Geriatr Soc. 2017;66(1):92-9.

25. Chan RC, Hoosain R, Lee TM, Fan YW, Fong D. Are there sub-types of attentional deficits in patients with persisting post-concussive symptoms? A cluster analytical study. Brain Inj. 2003;17(2):131-48.

26. BENJAMINI Y, HOCHBERG Y. Controlling the false discovery rate-a practical and powerful approach to multiple testing. J Royal Stat Soc Series BMethodological. 1995;57(1):289-300

27. Malek-Ahmadi M, Powell JJ, Belden CM, O'Connor K, Evans L, Coon DW Nieri W. Age- and education-adjusted normative data for the Montreal cognitive assessment (MoCA) in older adults age 70-99. Neuropsychol Dev Cogn B Aging Neuropsychol Cogn. 2015;22(6):755-61.

28. Yancar DE, Ozcan T. Evaluating the relationship between education leve and cognitive impairment with the Montreal cognitive assessment test. PSYCHOGERIATRICS. 2015;15(3):186-90.

29. Amaral-Carvalho V, Caramelli P. Normative data for healthy middle-aged and elderly performance on the Addenbrooke cognitive examinationrevised. Cogn Behav Neurol. 2012;25(2):72-6.

30. Wu Y, Zhang D, Pang Z, Oksuzyan A, Jiang W, Wang S, Li S, Kruse T, Christensen K, Tan Q. Gender-specific patterns in age-related decline in general health among Danish and Chinese: a cross-national comparative study. Geriatr Gerontol Int. 2012;12(3):431-9.

31. Lei $X$, Smith JP, Sun X, Zhao Y. Gender differences in cognition in China and reasons for change over time: evidence from CHARLS. J Econ Ageing. 2014; 4:46-55.

32. Lei $X, \mathrm{Hu} Y$, McArdle JJ, Smith JP, Zhao Y. Gender differences in cognition among older adults in China. J Hum Resour. 2012;47(4):951-71.

33. Chang ES, Dong X. A battery of tests for assessing cognitive function in U.S Chinese older adults-findings from the PINE study. J Gerontol A Biol Sci Med Sci. 2014;69(Suppl 2):S23-30.

34. Hoogendam YY, Hofman A, van der Geest JN, van der Lugt A, Ikram MA. Patterns of cognitive function in aging: the Rotterdam study. Eur J Epidemiol. 2014;29(2):133-40.

35. Proust-Lima C, Amieva H, Letenneur L, Orgogozo JM, Jacamin-Gadda H, Dartigues JF. Gender and education impact on brain aging: a general cognitive factor approach. Psychol Aging. 2008;23(3):608-20.

36. Matos GM, Pinho MS, Rodrigues SM. Effects of socio-demographic variables on performance on the Cambridge neuropsychological automated tests for the assessment of dementia and Portuguese norms for older adults living in retirement homes. Clin Neuropsychol. 2016; 30(2):284-317

37. Li R. Why women see differently from the way men see? A review of sex differences in cognition and sports. J Sport Health Sci. 2014;3(3):155-62.

38. Laws KR, Irvine K, Gale TM. Sex differences in cognitive impairment in Alzheimer's disease. World J Psychiatry. 2016;6(1):54-65.
39. Li R, Singh M. Sex differences in cognitive impairment and Alzheimer's disease. Front Neuroendocrinol. 2014;35(3):385-403.

40. Weir D, Lay M, Langa K. Economic development and gender inequality in cognition: a comparison of China and India, and of SAGE and the HRS sister studies. J Econ Ageing. 2014;4:114-25.

41. Lipnicki DM, Crawford JD, Dutta R, Thalamuthu A, Kochan NA, Andrews G Lima-Costa MF, Castro-Costa E, Brayne C, Matthews FE, et al. Age-related cognitive decline and associations with sex, education and apolipoprotein E genotype across ethnocultural groups and geographic regions: a collaborative cohort study. PLoS Med. 2017;14(3):e1002261.

42. Van der Elst W, Van Boxtel MP, Van Breukelen GJ, Jolles J. The Stroop colorword test: influence of age, sex, and education; and normative data for a large sample across the adult age range. Assessment. 2006;13(1):62-79.

43. Lee J, Shih R, Feeney K, Langa KM. Gender disparity in late-life cognitive functioning in India: findings from the longitudinal aging study in India. Gerontol B Psychol Sci Soc Sci. 2014;69(4):603-11.

44. Lu J, Li D, Li F, Zhou A, Wang F, Zuo X, Jia XF, Song H, Jia J. Montreal cognitive assessment in detecting cognitive impairment in Chinese elderly individuals: a population-based study. J Geriatr Psychiatry Neurol. 2011;24(4):184-90.

45. Tan JP, Li N, Gao J, Wang LN, Zhao YM, Yu BC, Du W, Zhang WJ, Cui LQ, Wang QS, et al. Optimal cutoff scores for dementia and mild cognitive impairment of the Montreal cognitive assessment among elderly and oldest-old Chinese population. J Alzheimers Dis. 2015;43(4):1403-12.

46. Wang Q, Sun J, Ma X, Wang Y, Yao J, Deng W, Liu X, Collier DA, Li T. Normative data on a battery of neuropsychological tests in the Han Chinese population. J Neuropsychol. 2011;5(Pt 1):126-42.

47. Collinson SL, Fang SH, Lim ML, Feng L, Ng TP. Normative data for the repeatable battery for the assessment of neuropsychological status in elderly Chinese. Arch Clin Neuropsychol. 2014;29(5):442-55.

48. Van Breukelen GJ, Vlaeyen JW. Norming clinical questionnaires with multiple regression: the pain cognition list. Psychol Assess. 2005;17(3):336-44.

49. Zachary RA, Gorsuch RL. Continuous norming: implications for the WAIS-R. J Clin Psychol. 1985;41(1):86-94.

50. Shirk SD, Mitchell MB, Shaughnessy LW, Sherman JC, Locascio JJ, Weintraub S, Atri A. A web-based normative calculator for the uniform data set (UDS) neuropsychological test battery. Alzheimers Res Ther. 2011;3(6):32.

51. Clark LR, Koscik RL, Nicholas CR, Okonkwo OC, Engelman CD, Bratzke LC, Hogan KJ, Mueller KD, Bendlin BB, Carlsson CM, et al. Mild cognitive impairment in late middle age in the Wisconsin registry for Alzheimer's prevention study: prevalence and characteristics using robust and standard neuropsychological normative data. Arch Clin Neuropsychol. 2016; https:// doi.org/10.1093/arclin/acw024

52. Ritchie LJ, Frerichs RJ, Tuokko H. Effective normative samples for the detection of cognitive impairment in older adults. Clin Neuropsychol. 2007;21(6):863-74.
Ready to submit your research? Choose BMC and benefit from:
- fast, convenient online submission
- thorough peer review by experienced researchers in your field
- rapid publication on acceptance
- support for research data, including large and complex data types
- gold Open Access which fosters wider collaboration and increased citations
- maximum visibility for your research: over $100 \mathrm{M}$ website views per year
At $\mathrm{BMC}$, research is always in progress. 